ИЗВЕСТИЯ АКАДЕМИИ НАУК ЭСТОНСКОП ССР. ТОМ 30 Химия. 1981, № 3

\title{
ВЫСОКОСКОРОСТНОЕ ПОЛУКОКСОВАНИЕ КУКЕРСИТА
}

\author{
(Представил О. Эйзен)
}

В работе ['] исследовалось влияние скорости нагрева в интервале $5-50{ }^{\circ} \mathrm{C} /$ мин на выход и состав продуктов термического разложения кукерсита. Ниже, в дополнение к имеющимся ранее сведениям, приводятся данные о термической деструкции концентрата сланца в условиях высокоскоростного (около $10^{5} \%$ мин) нагрева.

Флотационный концентрат кукерсита (\%: влага 1,1 ; зола 9,5 ; углекислота карбонатов 1,0$)$ подвергали высокоскоростному полукоксованию на установке и по методу Энергетического научно-исследовательского института им. Г. М. Кржижановского, описанному в $\left[{ }^{2}\right]$, в потоке азота. Температура стенки реактора составляла $500^{\circ}$, теплоносителя $560^{\circ}$, продолжительность пребывания пылевидного сланца в реакторе - 0,13 c. Смолу полукоксования обесфеноливали и разделяли на групповые компоненты методом тонкослойной хроматографии по методике [3], тонкослойные фракции анализировали газохроматографически с применением колонок различной полярности. Таким же образом исследовали смолу, полученную в сравнительном опыте полукоксования концентрата сланца в стандартных условиях (по ГОСТу 3168-66). Данные о выходе пирогенетической воды и смолы вместе с характеристикой последней в сравнении со смолой полукоксования сланца в реторте Фишера приведены в табл. 1, состав газа полукоксования (без теплоносителя) приведен в табл. 2. Газохроматографический анализ показал, что алифатические углеводороды смолы высокоскоростного полукоксования кукерсита отличаются от соответствующей группы соединений в смоле, образующейся при медленном нагреве, не только низким содержанием их, но и сдвигом концентрационного максимума $\mu$-алканов от $\mathrm{C}_{7} \mathrm{~K}_{12}$ (рис. 1), а также очень низким содержанием $\alpha$-олефинов (отношение $\mu$-1-алкены : $\mu$-алканы составляют $0,36: 1$ вместо 0,79:1 в смоле стандартного режима) и повышенной относительной концентрацией $H$-2-алкенов (особенно $\mathrm{C}_{11}$ и $\mathrm{C}_{13}$ ), по сравнению с H-1-алкенами. Во фракции алкилпроизводных бензола исследовавшейся смолы максимум концентрации приходится на соединения $\mathrm{C}_{15}$ и $\mathrm{C}_{16}$, т. е. аналогично алифатическим углеводородам концентрационный максимум сдвинут в область соединений с более высокой молекулярной массой. Состав конденсированных ароматических углеводородов мало зависит от скорости нагрева. Своеобразием алифатических кетонов в смоле высокоскоростного полукоксования (рис. 2), является то, что $\mathrm{H}$-2-алканонов в них меньше, чем изомеров с иным расположением карбонильной группы при большей средней длине цепи кетонов. Фенолы исследовавшейся смолы отличаются от присутствующих в стандартной смоле низким содержанием одноатомных фенолов; состав 
Таблица 1

Характеристика смол полукоксования кукерсита при различной скорости нагрева

\begin{tabular}{c|c|c}
\hline Показатели & $\begin{array}{c}\text { Высокоскорост- } \\
\text { ное полукок- } \\
\text { сование }\end{array}$ & $\begin{array}{c}\text { Полукоксова- } \\
\text { ние при стан- } \\
\text { дартном режнме }\end{array}$ \\
\hline
\end{tabular}

Выход на кероген, вес. \%

вода разложения смола + газбензин

плотность $Q_{4}^{20}$ Характеристика смолы:
показатель преломления $n_{D}^{20}$

Элементный состав, вес. \%:

углерод

водород

cepa

кислород + азот (по разности)

атомное отношение $\mathrm{H} / \mathrm{C}$

Групповой химический состав, вес. \%

неароматические углеводороды

одноядерные ароматические углеводороды

конденсированные ароматические углеводороды

нейтральные кислородные соединения

кислотные соединения

$\begin{array}{rr}8,9 & 5,0 \\ 55,2 & 65,3\end{array}$

1,0058

0,9385

1,5608

1,5221

$\begin{array}{rr}82,7 & 82,9 \\ 9,7 & 10,2 \\ 0,7 & 0,8 \\ 6,9 & 6,1 \\ 1,41 & 1,48\end{array}$

$\begin{array}{rr}6 & 17 \\ 2 & 7 \\ 18 & 18 \\ 62 & 35 \\ 12 & 23\end{array}$

Таблица 2

Состав газа полукоксования кукерсита при различной скорости нагрева

\begin{tabular}{|c|c|c|c|c|c|c|c|c|c|c|c|c|c|}
\hline \multirow[b]{2}{*}{ 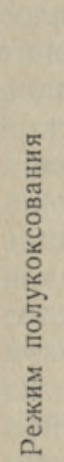 } & \multicolumn{11}{|c|}{ Компоненты, об. \% } & \multirow[b]{2}{*}{ 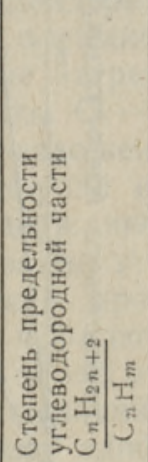 } & \multirow{2}{*}{ 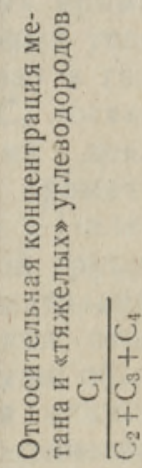 } \\
\hline & 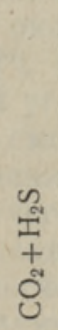 & ᄋ & $I^{a}$ & $\bar{J}$ & $\frac{I_{j}^{\circ}}{J^{\prime}}$ & $\frac{I^{\infty}}{v^{\infty}}$ & $\frac{0}{3}$ & 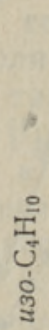 & 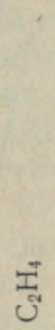 & 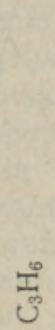 & 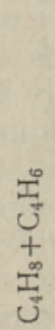 & & \\
\hline
\end{tabular}

Высоко-

скорост-

ной

нагрев

Стан-

$18,5 \quad 2,9 \quad 1,1 \quad 3,3 \quad 16,5 \quad 12,0 \quad 8,2 \quad 0,2$

$\begin{array}{llll}8,5 & 14,4 & 14,4 & 1,17\end{array}$

0,04

дартный

режим

нагрева

$38,7 \quad 6,8$

$3,7 \quad 18,6 \quad 11,8 \quad 5,1$

$2,2 \quad 0,1$

$5,9 \quad 4,3 \quad 2,8$

2,82

0,65

5-н-алкилпроизводных резорцина обычный. Преобладание в смоле соединений с относительно длинной алифатической цепью объясняется, по всей вероятности, тем, что короткие боковые цепи, характеризую- 


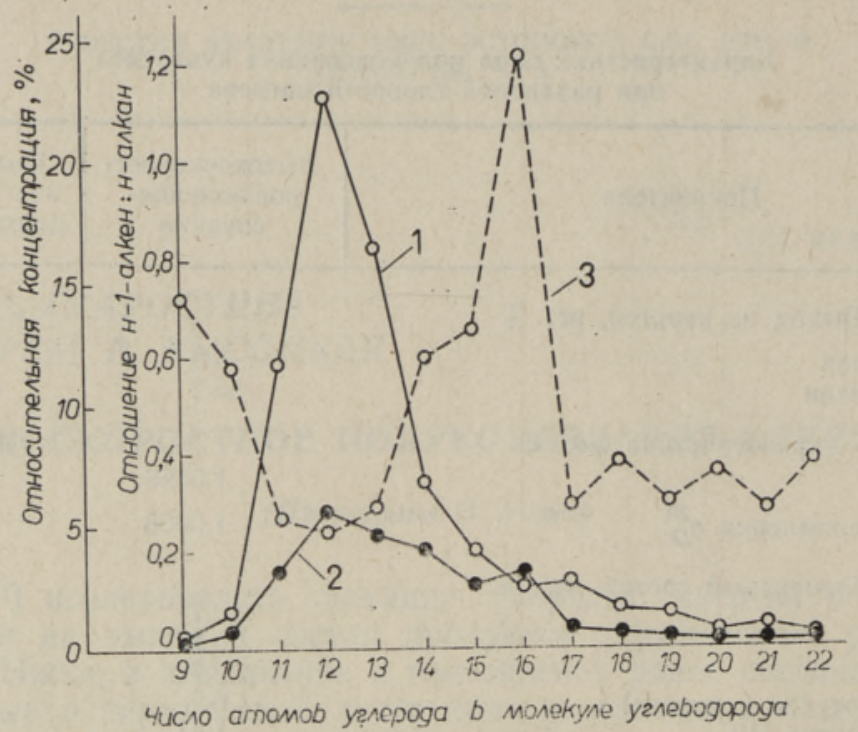

Рис. 1. Распределение по длине цепи $\boldsymbol{H}$-алканов (1) и $\mu$-1-алкенов (2) в смоле высокоскоростного полукоксования кукерсита (\% их суммарного содержания) и зависимость величины отношения $\boldsymbol{H}$-1-алкены: $\boldsymbol{H}$-алканы от числа атомов углерода в молекуле углеводорода (3).

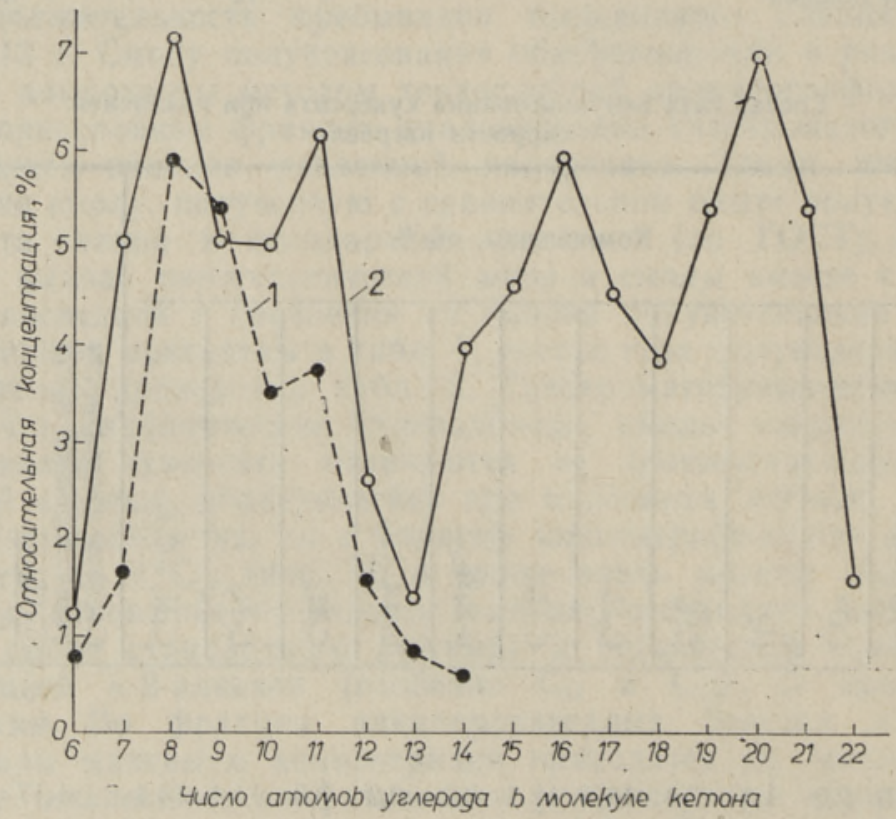

Рис. 2. Распределение по длине цепи метил-н-алкилкетонов (1) и симметричных или близких к ним н-алканонов (2) в смоле высокоскоростного полукоксования кукерсита (\% их суммарного содержания).

щиеся повышенной термостабильностью, остаются в составе более сложных продуктов деструкции керогена, в частности, кислородсодержащих соединений. 
Учитывая повышенную плотность смолы, образующейся при высокоскоростном нагреве, ее обогащенность кислородом и нейтральными кислородными соединениями (табл. 1), сдвиг концентрационного максимума алифатических и моноциклических ароматических углеводородов и алифатических кетонов в более высокомолекулярную область и преобладание в смоле симметричных и близких к ним $H$-алканонов над $H$-2-алканонами, а также низкое содержание одноатомных фенолов, эту смолу можно рассматривать как продукт менее глубокой деструкции керогена, не подвергшийся существенным вторичным превращениям. С другой стороны, судя по атомным отношениям $\mathrm{H} / \mathrm{C}$ и $(\mathrm{H}+\mathrm{O}) / \mathrm{C}$, исследовавшаяся смола является менее предельной, а выход ее на кероген ниже, чем при полукоксовании в реторте Фишера.

Предполагается, что при очень быстрсм нагреве керогена имеет место спонтанный распад макромолекул без заметного разделения процесса термических превращений на отдельные стадии. При этом циклическое ядро керогена до начала интенсивной фрагментации не успевает ароматизироваться в той же мере, как при медленном нагревании. Недостаточная степень ароматизации керогена, выражающаяся и в низком содержании водорода в газе разложения (табл. 2), не способствует стабилизации предсуществующих в керогене и образующихся в ходе деструкции гидроксильных групп в виде фенольных гидроксилов, в результате чего выход пирогенетической воды высок, а фенолов - низок (табл. 1). В связи с уменьшением роли отщепления кислорода в виде окислов углерода (табл. 2) происходит относительное обеднение смолы водородом, и, вследствие ограниченности ресурсов последнего, - уменьшение выхода смолы. Снижение содержания фенолов в смоле с повышением скорости нагрева отмечалось также в случае каменных $\left[{ }^{4}\right]$ и бурых [5] углей.

C представлением о заметной деградации алициклической части керогена и промежуточных продуктов распада до их ароматизации согласуются также данные о низком содержании одноядерных ароматических углеводородов в смоле и очень высоком - олефиновых углеводородов (37,3 вместо 9,5\% при стандартном режиме нагрева) в газе полукоксования. Известно, например, что углеводороды $\mathrm{C}_{1}-\mathrm{C}_{5}$ составляют около половины продуктов термического разложения декалина [ $\left.{ }^{6}\right]$. В пользу ограниченной роли миграции водорода с ароматизацией углеродного скелета говорит также низкое содержание $H$-1-алкенов в смоле: ранее было показано [ $\left.{ }^{7}\right]$, что формирование этой группы соединений приурочено в основном к стадии заметной ароматизации нелетучего остатка. С другой стороны, образование $\mu$-2-алкенов, относительная концентрация которых в исследовавшейся смоле выше обычной, легче связать со стадией малоселективного отщепления алкильных заместителей, когда в формировании летучих алифатических углеводородов может участвовать также углерод циклических структур. Интересно, что умеренное повышение скорости нагрева кукерсита приводит к некоторому возрастанию отношения $\boldsymbol{H}$-1-алкены: $\boldsymbol{H}$-алканы в смоле [1] (то же было отмечено и для каменных углей $\left.{ }^{8}\right]$ ), хотя общие ресурсы $н$-1-алкенов в смоле уменьшаются, как и при высокоскоростном полукоксовании.

Своеобразие термического разложения кукерсита при высокоскоростном нагреве в свете вышеизложенного можно рассматривать как следствие ограниченного развития стабилизационных процессов, играющих видную роль при деструкции как кукерсита [9], так и каменных углей $\left[{ }^{10}\right]$ в условиях медленного нагревания. 


\title{
ЛИТЕРАТ У Р А
}

1. У ров К., Клесмент И., Эйзен О. Изучение химического состава смолы скоростного полукоксования кукерсита. - Изв. АН ЭССР. Хим., Геол., 1974, т. 23 , № 2 , с. $99-104$.

2. Базарова Л. Н., Тер-Оганесян Г. Қ. Исследование высожоскоростного пиролиза канско-ачинского угля на установке с газовым теплоносителем. (Н.-и. энерг. ин-т. М., 1977; деп. 4 февр. 1978 г., № 439.) - В кн.: Депонированные рукописи (естественные и точные науки, техника). М., 1978, № 5 , c. 88 .

3. Klesment, I. Application of chromatographic methods in biogeochemical investigations. - J. Chromatogr., 1974, v. 91, N 2, p. 705-713.

4. Бронштейн А. П., Мака ров Г. Н., Платонов В. В. Влияние условий нагревания на образование кислородсодержащих соединений кузнецких жирных углей. - Хим. тверд. топл., 1974, № 5, с. 20-27.

5. Химия скоростного пиролиза бурых углей. Новосибирск, 1976, с. 62-77.

6. Раковский В. Е., К а ганович Ф. Л., Новичков а Е. Л. Химия пирогенных процессов. Минск, 1959, с. 176.

7. У ров К. Э. Термическая деструкция сланца-кукерсита в вакууме. - Хим. тверд. топл., 1976 , № 5 , с. $33-38$.

8. Pichler, H., S $\mathrm{chw}$ arz, G. Untersuchung flüssiger und gasförmiger Produkte der Steinkohlenschwelung. II. Zusammensetzung einer Wirbelschicht und eines Fischer-Schwelteers. - Brennstoff-Chemie, 1969, Bd. 50, S. 72-78.

9. А а рн а А. Я., Р и к кен Ю. Т. О механизме низкотемпературного разложения сланца-кукерсита. - Тр. Таллинск. политехн. ин-та, 1957, сер. А, № 97, c. $53-67$.

10. Синце рова Л. Г., Кекин Н. А. Начальная стадия термохимических превращений веществ каменных углей. - В кн.: Теория и практика подготовки и коксования углей. М., 1976, № 5, с. $76-87$.

\section{Ннститут химии \\ Академии наук Эстонской ССР

\begin{abstract}
Энергетический научно-исследовательский институт и... Г. М. Кржижановского
\end{abstract}

Поступила в редакцию $3 / \mathrm{X} 1980$

\author{
K. UROV, N. STAROSTINA, \\ Ada LISTROM, V. VOSSOTSKAJA
}

w........

\section{KUKERSIIDI ULIKIIRE UTMINE}

Kukersiidist kahel erineval kuumutamiskiirusel (5 ja ligikaudu $10^{5}{ }^{\circ} \mathrm{C} / \mathrm{min}$ ) saadud ōlide vōrdleva analüüsi andmeil sisaldab ülikiirel utmisel saadav ôli vähem alifaatseid (eeskätt $n$-1-alkeene) ja ühetuumalisi aromaatseid süsivesinikke ning fenoole $(12 \%)$, kuid rohkem neutraalseid hapnikuühendeid $(62 \%)$, uttegaas aga on rikkam küllastumatute süsivesinike poolest $(37 \%)$, sisaldades tavalisest vähem süsinikoksiidi ja -dioksiidi, vesinikku ning metaani. Oletatakse, et ülikiire utmise produktide omapära on tingitud kerogeeni alitsüklilise osa ulatuslikust lagunemisest enne tema aromatiseerumist.

\author{
K. UROV, N. STAROSTINA, \\ Ada LISTROM, V. VOSSOTSKAYA
}

\section{HIGH-RATE SEMICOKING OF KUKERSITE}

With an increase in the rate of heating kukersite from 5 to approximately $10^{5}{ }^{\circ} \mathrm{C} / \mathrm{min}$, the concentration of neutral oxygen-containing compounds in the shale semicoking oil increases up to $62 \mathrm{wt} . \%$ and the content of aliphatic hydrocarbons (n-1-alkenes in the first place), alkyl derivates of benzene and phenols (12 wt.- \% in oil) diminishes, the concentration of unsaturated hydrocarbons in the gas produced grows (up to 37 vol.- $\%$ ), and that of the carbon monoxide, carbon dioxide, hydrogen and methane decreases. It is supposed that the specific character of the shale high-rate heating products is caused by the extensive decomposition of the alicyclic part of kerogen prior to its aromatization, 